\title{
The Development of Literacy Achievement Evaluation in School Literacy Movement
}

\author{
Yuni Pantiwati \\ University of Muhammadiyah Malang \\ yuni_pantiwati@yahoo.co.id
}

\begin{abstract}
This study would explain assessment of literacy achievement in School Literacy Movement. The study definitely aimed at: (1) describing the development of literacy assessment in School Literacy Movement; (2) describing the development of assessment tools used for literacy achievement in School Literacy Movement; and (3) examining the validity and reliability aspect of literacy achievement in School Literacy Movement. Mainly, this study applied Research and Development Design. It also consisted of two stages, namely introduction and developmental stages. The developmental stage should go through (1) determining measurement tools; (2) validating to the expert; (3) testing restricted scale; and (4) testing on a wide scale. The result of the introduction stage showed that assessment tools of literacy achievement in the school did not correspond with the guideline of School Literacy Movement. Meanwhile, the result of the developmental stage showed that literacy achievement has reached 71 items. It also consisted of adjustment (24 items), development (22 items), and learning stages ( 25 items). Thus, the result of validity test was valid and reliable.
\end{abstract}

Keywords: literacy assessment,

\section{INTRODUCTION}

The Ministry of Education and Culture has issued the regulation No. 23 of 2015 about character education. According to that regulation, the General Directorate of Primary and Secondary Education has launched the program 'School Literacy Movement'. This program aims at accessing, understanding, and implementing educational programs through reading, listening, writing, and speaking activities.

School Literacy program has three stages, namely adjustment, development, and learning. The assessment tool used to reach literacy achievement is a guideline of SLM. However, the instrument used to evaluate the implementation of School Literacy Movement still does not exist. According to Kisyani (2016), the evaluation of School Literacy Program is periodically conducted in every semester. Thus, the result will determine whether the school has implemented from adjustment stage to learning stage or not. The school at the development or learning stage could design the planning, assessment, and evaluation based on related stage.

The result of the first study showed that the school has already implemented three stages of School

Literacy Program. The school also has implemented the evaluation; however, the evaluation system is still not proper. In this case, literacy team deliberates the decision based on those three stages. It occurs due to the regulation restricted the school, not the student.

Based on the finding, furthermore, the researcher tries to develop authentic evaluation to measure literacy achievement for the student. Pratiwi (2016) reveals that the concept of authentic evaluation has already corresponded with learning model which emphasizes students literacy, independence, and participation.

Therefore, the aims of this study are (1) to describe the development of literacy assessment in School Literacy Movement; (2) to describe the development of assessment tools used for literacy achievement in School Literacy Movement; and (3) to examine the validity and reliability aspect of literacy achievement in School Literacy Movement.

\section{METHODS}

This study was conducted at one of Junior High Schools in Malang City. This study applied Research and Development design (R\&D). According to Borg and Gall (1983), the stages of the study consist of introduction and development.

Introduction stage is defined as an evaluation instrument to analyze the development needs of literacy achievement. This stage is initiated from a validated performance by Junior High School teachers and experts. Then, it is followed by small and big group trials.

The assessment tool of literacy achievement is an implementation of School Literacy Movement for adjustment, development, and learning stages. Moreover, the indicator is developed from a certain 
variable which is derived from the purpose of School Literacy Movement (Table 1). Each item consists of one statement with two alternatives, 'Yes' and 'No' answers. The item with the answer 'Yes' gets 1 score while the 'No' answer gets zero score. The reliability of assessment tool (instrument) is analyzed by using Kuder and Richardson (KR-20) formulation. The scoring used in the evaluation process will produce dichotomy score (0-1). If the score is getting closer to 1 , then the instrument will be more reliable. According to Surapranata (2004:114), the value of $-20>0.90$ (adapted from Kuder and Richardson) is considered reliable. The formulation is presented below.

$$
r_{11=\frac{k}{k-1}}\left(\frac{s^{2}-\sum p q}{s^{2}}\right)
$$

Notes:

$n_{11}=$ reliability test

$p=$ the number of the right answer

$q=$ the number of the wrong answer

$\sum p q=$ total multiplication betwen $p$ and $q$

$k=$ the rumber of test item

Particularly, the valid instrument will be followed by a certain group test with 12 students using purposive sampling technique.

The result of the control group is revised and continued to the wide-scale test with the number of 55 seventh grade students at one of Junior High Schools in Malang by using cluster random sampling technique.

\section{RESULTS}

The result of the first study showed that learning stage of literacy achievement reaches 100 percent assuming that all students joined 30 times literacy program in one semester. The student who reads 21 times is $70 \%$ assuming that six books finishing are considered the passing criterion of the program. Furthermore, the student who passes the program will receive a certificate for acquiring academic transcript. In the learning stage, the report of literacy achievement is composed by the academic advisor and granted to literacy team at the end of the month. The evaluation system of this finding. still does not meet the evaluation in School Literacy Movement.

This evaluation does not correspond with the right system. Moreover, the assessment of literacy achievement has not been established yet in SLM guideline. Thus, the innovation and creation are still underdeveloped. Kisyani et.al. (2016) state that the assessment should be conducted every week to examine the result of the evaluation program.

The result of validity test should be revised in the form of language simplifying, reducing item, scale using 'Yes' and 'No' answers, and competency orientation. After obtaining the result of validity test, the researcher continues with reliability test. Afterward, the result of KR-20 is .83 which showed that reliability coefficient is considered significant (above the standard of .8).

\title{
Table 1. Assessment of Literacy Achievement in School Literacy Movement
}

\section{Adjustment Stage}

\author{
Reading habit \\ 1 I read any book less than 15 minutes every day. \\ 2 I read any book for 15-30 minutes every day. \\ 3 I read any book for 30-60 minutes every day. \\ 4 I read any book more than 60 minutes every day. \\ Improving the passion for reading outside of school hours \\ 1 I have read any book outside of school hours. \\ 2 I love reading any book outside of school hours. \\ 3 I always read any book outside of school hours. \\ $4 \quad$ I try to spare my time for reading any book outside of school hours. \\ 5 I am comfortable to read any book outside of school hours. \\ Improving reading comprehension \\ 1 I understand the content of the book if I read more. \\ 2 I have difficulty to comprehend the reading content. \\ 3 I cannot comprehend reading content (consider the scaling and the order of choices)
}


$4 \quad$ I comprehend the reading content but I only get some.

5 I comprehend the reading content and I get so many things from it.

Building self-confidence as a good reader

1 Before the existence of SLM Program, I read the literature book well.

2 I read the literature book well after following SLM Program.

3 My reading skill is better than others.

4 I am now a good reader.

5 I have got an achievement related to the reading activity.

\section{Utilizing reading sources}

1 I read less than one book every month.

2 I read one book every month.

3 I read 2-5 books every month.

4 I read more than five books on the same topic every month.

5 I read more than five books on different topics every month.

\section{Development Stage}

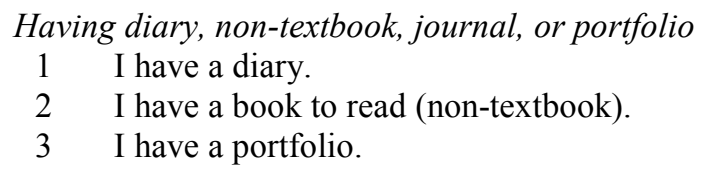

Increasing student's skill in responding Enrichment Book in both written and verbal comprehensions

1 After reading, I give a written comment.

2 After reading, I give a verbal comment.

3 After my friend telling a story, I give a comment.

$4 \quad$ I have once told a story to my friends.

5 I give written and verbal comments.

Building an interaction between student and teacher regarding the reading source

1 I discuss with a friend in literacy activity.

2 I ask a question about reading content to my friend.

3 I explain reading content to my friend.

4 I ask a question about reading content to the teacher.

5 I discuss with the teacher about reading content.

Preparing the student to create critical, analytical, creative, and innovative thinking.

1 To face the problem, I deliberate a decision to accept, deny, or question the truth of the statement.

2 I try to create perfection and something different to my friend.

3 I answer the question by finding, proving, analyzing the relation and showing the truth.

4 I utilize surrounding sources to create a valuable and favorable work for all people.

Encouraging the student to discover the relationship between three components (book, individual, and environment)

1 After reading a topic, I reflect on myself.

2 After reading, I relate the topic to my family.

3 After reading, I relate the topic to the school.

4 After reading, I relate the topic to my friends.

5 After reading, I think about the moral values. 


\section{Learning Stage}

Developing reading skill and relating to personal experiences in building successful learner.

1 I discover new ways of comprehending textbooks.

2 I relate reading content to my personal experience.

3 I utilize the information from textbooks in solving the problem.

4 I utilize the information from textbooks in creating something new.

5 I utilize the information from textbooks in adapting to the environment.

\section{(No aspect here?)}

1 I focus on the question-answer explanation and try out.

2 I consider the reliable source.

3 Before making a conclusion, I think, reflect, and consider it first.

4 Before deliberating consideration, I study the case problem frequently.

$5 \quad$ I plan the strategy before determining action and interaction with others.

Managing communication skills (verbal, written, visual, and digital) by reading textbooks

1 After reading a textbook and non-textbook, I deliberate the information in written form

2 After reading a textbook and non-textbook, I deliberate the information verbally.

3 After reading a textbook and non-textbook, I deliberate the information through printed media, such as picture, poster, etc.

4 After reading a textbook and non-textbook, I deliberate the information through online media, such as Facebook, Whatsapp, Email, Instagram, etc.

5 After reading a textbook and non-textbook, I deliberate the information in various ways.

\section{(No aspect here?)}

1 I have one work from reading activity.

2 I have 2-5 works from reading activity.

3 I have more than five works from reading activity.

4 I have a work that has been published.

\section{(No aspect here?)}

1 I have a reading community that actively participates in regional level.

2 I have reading community participating in regional level which has already published work or held an exhibition.

3 I have a reading community that actively participates in provincial level.

4 I have reading community participating in provincial level which has already published work or held an exhibition.

5 I have a reading community at the national level.

6 I have reading community participating at national level which has already published work or held an exhibition. 
To achieve successful literacy activity, teacher plays an important role in monitoring learning process as stated in the 2013 Curriculum. However, the teacher of Junior High School in Malang City does not have enough understanding of scientific literacy (Pantiwati \& Husamah, 2015). Therefore, teacher's ability is a crucial factor in literacy learning process (Albers et al., 2016). Teachers' assessment literacy is arguably fundamental to their ability to successfully engage with multiple expectations of assessment and to facilitate assessment as a process that continually supports learning. In another hand, Sivakumar Alagumalai (2014) also comments 'In any educational context, teachers' assessment literacy is of prime importance in order to ascertain learning. Results reported in this article have shown that the ALI has some psychometric qualities that make it useful for measuring teachers' assessment literacy'.

Basically, teacher's understanding is expected to enhance student's knowledge through literacy program in the evaluation stage. According to Shwartz et. al. (2006), the assessment of literacy achievement has three types, namely functional literacy, civic literacy, and cultural literacy. The assessment should concern on socio-cultural aspect, technology utilization, and student's adjustment.

Purcell-Gates et. al. (2012) revealed that teaching students how to use the real-life text is real life only when it is part of an activity in which the students are reading/writing the text for a real-life purpose. The assessment is deeply related to the social interaction between student, teacher, and environment. They also explain that KSIs (Knowledge Sharing Interactions) are generated and supported by collaborative opportunities to exchange ideas, co-construct knowledge, offer practical classroom applications and gain insight into important critical literacy issues.

Regarding long life education, the students should be equipped with supporting facilities to succeed learning sustainability. As stated by Thoman and Jolls (2004), the convergence of media and technology in a global culture is changing the way we learn about the world and challenging the very foundations of education. Media literacy education provides a framework and pedagogy for the new literacy needed for living, working, and citizenship in the 21 st century. Moreover, it paves the way to mastering the skills required for lifelong learning in a constantly changing world. Therefore, literacy program is highly needed for students.

\section{CONCLUSION}

The findings of the introduction study showed that the teacher faces the problem while measuring literacy achievement due to limited assessment tools. Therefore, the researcher designed the instrument used for an evaluation. Meanwhile, the result of the developmental stage showed that literacy achievement has reached 71 items. It also consists of adjustment (24 items), development (22 items), and learning stages (25 items). Thus, the result of validity test is seen valid and reliable.

\section{REFERENCES}

[1] Albers, Peggy. et.al, 2016. From Affinity and Beyond: A Study of Online Literacy Conversations and Communities. Journal of Literacy Research 2016, Vol. 48 (2) 221-250. jlr.sagepub.com.

[2] Hailaya, Wilham and Sivakumar Alagumalai. 2014. Examining the utility of Assessment Literacy Inventory and Its Portability to Education Systems in the AsiaPacific Region. Australian Journal of Education 2014, Vol. 58(3) 297-317 aed.sagepub.com.

[3] Kisyani, L, et al. 2016. Manual Guideline of School Literacy Movement for Junior High School Education. Jakarta: General Directorate of Primary and Secondary Education.

[4] Pantiwati, Yuni dan Husamah. 2015. A Guideline of Literacy Movement in Junior High School Education. Proceeding. $6^{\text {th }}$ Pedagogy International Seminar. UPI Bandung 15-17 September 2015.

[5] Pratiwi. 2016. A Guideline of Literacy Movement in Junior High School Education. Jakarta: The Ministry of Education and Culture.

[6] Purcell-Gates, V. et al. 2012. Measuring Situated Literacy. Journal of Literacy Research 44 (4) 396-425

[7] Sugiyono. 2012. Quantitative-Qualitative Research Methodology and R \& D. Bandung: Alfabeta.

[8] Surapranata. 2004. An Analysis on Validity, Reliability, and Interpretation Test. Bandung: Rosda. 
[9] Thoman, Elizabeth and Tessa Jolls. 2004. Media Literacy - A National Priority for a Changing World. Center for Media Literacy. American Behavioral Scientist, Vol. 48 No. 1, September 2004 18-29. 
